\title{
Uso racional de antimicrobianos en tiempos de COVID-19 en Perú: rol de los programas de optimización del uso de antimicrobianos e intervenciones desde el punto de vista de control de infecciones
}

Pérez-Lazo G*1,2; Soto-Febres F ${ }^{1,2}$; Morales-Moreno A ${ }^{1,2}$; Cabrera-Enríquez John A ${ }^{1,3}$; Díaz-Agudo $\mathrm{J}^{1,4}$, Rojas R ${ }^{1,4}$; ArenasRamírez B ${ }^{1,5}$; Illescas $R^{1,2}$

\section{RESUMEN}

La resistencia antimicrobiana (RAM) es una pandemia adicional de lenta evolución que precede a la pandemia de COVID-19 y continuará cuando esta termine. Sin embargo, en países como Perú, donde existe un alto consumo y prescripción inadecuada de antimicrobianos, puede pasar desapercibida y se puede esperar, en el futuro, un escenario más desafiante. Los programas de optimización de uso de antimicrobianos (PROA) son equipos multidisciplinarios de profesionales que tienen como objetivo retardar la aparición de organismos multirresistentes a través de estrategias como la auditoría de prescripciones o la creación de algoritmos de tratamiento antimicrobiano basados en las tasas locales de RAM. La dificultad en el diagnóstico oportuno de coinfecciones o superinfecciones en el curso clínico y progresión de la COVID-19 predisponen al uso inadecuado de antimicrobianos, lo que obliga a los PROA a adaptar sus estrategias en este panorama cambiante. En Latinoamérica, los PROA no solo tienen que fomentar el cambio de comportamiento en los prescriptores de antimicrobianos, sino también luchar contra la epidemia de información falsa (infodemia) y las campañas de desinformación sobre la COVID-19. Además, la pobre cultura local de prevención y control de infecciones obliga a revisar estrategias para mitigar el impacto posterior en la RAM.

Palabras clave: COVID-19; Programas de optimización del uso de los antimicrobianos; Sobreinfección; Coinfección; Control de infecciones (Fuente: DeCS BIREME).

\section{Rational use of antimicrobials during COVID-19 times in Peru: role of antimicrobial stewardship programs and interventions in terms of infection control}

\begin{abstract}
Antimicrobial resistance (AMR) is an additional slow-evolving pandemic that precedes the COVID-19 pandemic and will continue when it ends. However, in countries like Peru, where high consumption and inadequate prescription of antimicrobials occur, AMR may go unnoticed and a more challenging future scenario can be expected. Antimicrobial stewardship programs (ASPs) consist of multidisciplinary teams of professionals that aim to slow down the emergence of multidrug-resistant organisms through strategies such as prescription auditing or creation of antimicrobial treatment guidelines based on local AMR rates. The difficulty in the timely diagnosis of co-infections or superinfections in the clinical course and progression of COVID-19 leads to inappropriate use of antimicrobials, forcing ASPs to adapt their strategies in this changing scenario. In Latin America, ASPs not only have to promote behavior change in antimicrobial prescribers but also fight the epidemic of false information (infodemic) and disinformation campaigns on COVID-19. Furthermore, poor-quality infection prevention and control principles require evaluating strategies to mitigate the subsequent impact on AMR.
\end{abstract}

Keywords: Coronavirus infections; Antimicrobial stewardship; Superinfection; Coinfection; Infection control (Source: MeSH NLM).

1 Hospital Nacional Guillermo Almenara Irigoyen-EsSalud, Programa de Optimización de Uso de Antimicrobianos. Lima, Perú.

2 Hospital Nacional Guillermo Almenara Irigoyen-EsSalud, Servicio de Infectología. Lima, Perú.

3 Hospital Nacional Guillermo Almenara Irigoyen-EsSalud, Servicio de Pediatría. Lima, Perú.

4 Hospital Nacional Guillermo Almenara Irigoyen-EsSalud, Farmacia Clínica. Lima, Perú.

5 Hospital Nacional Guillermo Almenara Irigoyen-EsSalud, Unidad de Prevención y Control de infecciones. Lima, Perú.

* Autor corresponsal. 


\section{INTRODUCCIÓN}

Hasta la fecha no se ha demostrado que ningún medicamento sea efectivo en el tratamiento de la enfermedad del coronavirus 2019 (COVID-19). El documento técnico Prevención, diagnóstico y tratamiento de personas afectadas por COVID-19 en el Perú considera el uso de azitromicina más hidroxicloroquina para el tratamiento de pacientes con enfermedad moderada/severa (1). Adicionalmente, si existe sospecha de infección bacteriana concomitante, se recomienda el uso empírico de antimicrobianos como ceftriaxona, cefuroxima o piperacilina/tazobactam ${ }^{(1,2)}$. En el Perú, es preocupante que se prescriban antimicrobianos en más de $70 \%$ de pacientes hospitalizados sospechosos o con diagnóstico confirmado de COVID-19 ${ }^{(3)}$. Este hecho es similar a lo que ocurre en China, donde el $95 \%$ de los pacientes recibe tratamiento antimicrobiano a pesar de la escasa evidencia de coinfección bacteriana asociada ${ }^{(4)}$.

El uso de antimicrobianos en la COVID-19 debería guiarse por las estrategias de los programas de optimización de uso de antimicrobianos (PROA) locales ${ }^{(5,6)}$. Estos son equipos multidisciplinarios conformados, principalmente, por profesionales de los servicios de infectología, microbiología y servicio farmacéutico, acompañados de miembros del equipo de control de infecciones, unidades de cuidados intensivos, entre otros ${ }^{(7)}$. Su rol es promover el uso adecuado de los antimicrobianos para contener la aparición de organismos multirresistentes y minimizar efectos adversos (toxicidad, candidemia, colitis por Clostridioides difficile), a través de estrategias como la auditoría prospectiva/restrictiva o construcción de algoritmos locales de terapia antimicrobiana con base en perfiles de resistencia antimicrobiana (RAM) de cada hospital ${ }^{(5,6)}$, entre otras. A pesar de que no hay recomendaciones formales para incluir a los PROA en situaciones de emergencia, estos pueden tener impacto en la respuesta frente a la pandemia de COVID-19 (5).

Consideramos que las recomendaciones locales de manejo de COVID-19 han obviado (adicionalmente al perfil de interacciones y posible toxicidad farmacológica) otros aspectos, como la RAM actual y posterior a la pandemia, el riesgo de superinfecciones y el probable rol de los antimicrobianos en la tormenta de citoquinas. En esta revisión discutimos algunos aspectos sobre el uso racional de antimicrobianos en pacientes con COVID-19, resaltamos el rol de los PROA y señalamos algunas intervenciones adicionales desde el punto de vista de control de infecciones.

\section{ESTRATEGIA DE BÚSQUEDA}

Se realizó una revisión narrativa de los ítems señalados bajo la búsqueda en la literatura en las bases de Pubmed, Google Scholar y Scielo. Se utilizaron los términos de búsqueda: "Antimicrobial stewardship",
"Superinfection", “COVID-19", "Coinfection", “Infection control". Se seleccionaron los artículos en inglés y español que abordaban la temática de interés. La búsqueda en las bases bibliográficas se realizó hasta el 29 de mayo de 2020, y se encontraron 112 artículos.

USO RACIONAL DE ANTIMICROBIANOS EN LA PANDEMIA DE COVID-19: ROL DE AZITROMICINA, DOXICICLINA E IVERMECTINA

\section{Azitromicina}

La azitromicina (macrólido) es un antimicrobiano recomendado en el manejo empírico de neumonía de la comunidad en pacientes sin factores de riesgo para Staphylococcus aureus meticilino-resistente o Pseudomonas aeruginosa ${ }^{(8)}$. La recomendación de azitromicina más hidroxicloroquina en el manejo de la COVID-19 está sustentada en el efecto sinérgico in vitro sobre SARS-CoV-2 reportado en un ensayo clínico abierto no aleatorizado que incluyó una muestra pequeña de pacientes, en el que se observó una reducción de la carga viral luego de tres días de tratamiento ${ }^{(9)}$.

El Instituto Nacional de Salud de Estados Unidos (NIH de sus siglas en inglés, National Institutes of Health) no recomienda, actualmente, la combinación de hidroxicloroquina y azitromicina fuera de ensayos clínicos, por el riesgo potencial de toxicidad (nivel de evidencia AllI) ${ }^{(10)}$. De 120 eventos adversos reportados en la red de farmacovigilancia de Francia por el uso de drogas "fuera de etiqueta" contra COVID-19, 80 \% estuvieron relacionados al uso de hidroxicloroquina (la mayoría de veces usada asociada a azitromicina) ${ }^{(11) .}$

La utilidad adicional de la azitromicina proviene de los reportes acerca de que su uso temprano, comparado con un placebo, reduce la severidad de infecciones respiratorias bajas en población pediátrica con infecciones recurrentes ${ }^{(12)}$. Million et al. describieron, en un estudio sin grupo control, que la combinación de ambas drogas es segura y está asociada con menor mortalidad, menor deterioro clínico y mínimo porcentaje de casos con persistencia viral de más de diez días cuando se administran tempranamente en el curso de la COVID-19 (13). Debido a estas limitaciones, carece de sustento sólido el intento de extrapolar estos beneficios a pacientes con COVID-19.

El rol de la azitromicina como inmunomodulador ha sido descrito en enfermedades pulmonares crónicas como fibrosis quística, bronquiectasias no fibrosis quística, enfermedad pulmonar obstructiva crónica (EPOC) y asma. Esto se debe a que disminuye la producción de citoquinas inflamatorias en fase aguda (IL-6, IL-8, TNF-a), a que promueve la resolución de inflamación crónica en fases posteriores y a su actividad directa sobre células epiteliales para mantener su función y 
Uso racional de antimicrobianos en tiempos de COVID-19 en Perú: rol de los

programas de optimización del uso de antimicrobianos e intervenciones desde el

punto de vista de control de infecciones

reducir la secreción de moco ${ }^{(14)}$. Un posible beneficio clínico en el síndrome de distrés respiratorio del adulto (SDRA) y sepsis en los pacientes con COVID-19 tampoco está documentado ${ }^{(15)}$.

Es posible predecir el impacto que tendrá el uso excesivo de azitromicina en la RAM de algunos patógenos luego de la pandemia, cuando su uso pueda ser aún menos efectivo. La tasa local de resistencia a macrólidos en cepas de neumococo obtenidas en pacientes hospitalizados en Lima es superior al $30 \%{ }^{(16)}$. Además, la información sobre la frecuencia de coinfecciones de SARS CoV-2 y patógenos respiratorios que justifiquen su empleo, como Mycoplasma pneumoniae, está escasamente documentada ${ }^{(17,18)}$.

\section{Doxiciclina}

La doxiciclina (tetraciclina semisintética) ha sido propuesta como potencial agente terapéutico contra el SARS-CoV-2 por distintos posibles mecanismos de acción: inhibición de entrada y fusión con la célula del huésped a través de inhibición de metaloproteinasas de matriz mediante secuestro de zinc ${ }^{(20)}$, inhibición de proteasa viral (basado en experiencia previa en dengue y chikungunya) ${ }^{(21,22)}$ y efecto inmunomodulador-antiinflamatorio en el parénquima pulmonar ${ }^{(23)}$.

A pesar de la prolongada experiencia en su uso, bajo costo, excelente disponibilidad por vía oral, espectro antimicrobiano y mejor perfil de seguridad (comparado con hidroxicloroquina y antirretrovirales), su uso en el tratamiento y prevención de formas severas de COVID-19 debe ser evaluado posteriormente a los resultados de ensayos clínicos aleatorizados que, actualmente, están en fase de reclutamiento en Francia y Estados Unidos (24).

La doxiciclina es considerada una opción terapéutica en el tratamiento empírico de neumonía de la comunidad sin factores de riesgo para S.aureus meticilino-resistente y Pseudomonas aeruginosa ${ }^{(8)}$. Tiene actividad sobre un amplio espectro de microorganismos, entre ellos, Streptococcus pneumoniae, Mycoplasma pneumoniae y Chlamydophila pneumoniae, pero con grados variables de resistencia en cada especie ${ }^{(25)}$.

Tomando como base la prevalencia de coinfecciones bacterianas/SARS-CoV-2 (8 \% durante admisión hospitalaria) ${ }^{(26)}$ y la tasa local de resistencia a tetraciclinas ( $20 \%-29 \%)$ en cepas de neumococo aisladas de pacientes con enfermedad neumocócica invasiva y portadores nasofaríngeos respectivamente ${ }^{(16,27)}$, es prudente un uso adecuado de este antimicrobiano en el contexto de la pandemia actual. Mycoplasma pneumoniae y Chlamydophila pneumoniae son patógenos sin prevalencia real estimada en Perú (28), y la información local sobre resistencia a tetraciclinas es nula, por lo que determinar un posible impacto posterior en su resistencia a este fármaco no es posible.

\section{Ivermectina}

El documento técnico peruano recomienda una dosis única de $6 \mathrm{mg} / \mathrm{mL}$ de ivermectina (1 gota o $200 \mu \mathrm{g}$ por kg de peso, con un máximo de 50 gotas) para casos leves de COVID-19, y por dos días en casos de enfermedad moderada-severa (1). Se sugiere que tiene actividad antiviral in vitro, con base en un ensayo en el que se logró la reducción de todo el material viral en 48 horas con una sola adición de $5 \mu \mathrm{M}$ de ivermectina a células Vero-hSLAM infectadas con el aislado SARS-CoV-2 Australia/VIC/01/2020 (29).

Sin embargo, los datos farmacocinéticos disponibles de la ivermectina indican que, en las dosis utilizadas para el manejo de la estrongiloidiasis, no es posible alcanzar las concentraciones inhibitorias de SARS-CoV-2 (30). Actualmente, se están realizando varios ensayos clínicos controlados para determinar la seguridad y eficacia clínica de ivermectina sola o como adyuvante de otros fármacos frente a COVID-19, con ocho ensayos en fase de reclutamiento ${ }^{(31)}$.

En Perú, el uso masivo de ivermectina sin evidencia clínica sólida reportada para el tratamiento, o incluso prevención de COVID-19, implica otras repercusiones (aumento de reacciones adversas, desabastecimiento, uso de productos veterinarios). A la fecha, el Centro Nacional de Farmacovigilancia y Tecnovigilancia (CENAFyT-Perú) ha recibido información de sospecha de reacciones adversas asociadas al uso de ivermectina, entre las que se señalan vértigo, náuseas, vómitos, somnolencia, mareos, flogosis y prurito ${ }^{(32)}$.

\section{INTERACCIONES ENTRE FÁRMACOS USADOS EN LA PANDEMIA DE COVID-19 EN PERÚ}

La prescripción en la comunidad abarca combinaciones de ivermectina, azitromicina e hidroxicloroquina, e incluso prednisona y warfarina como resultado de la sobreproducción de información acomodada, errónea o falsa (infodemia) ${ }^{(33,34)}$, lo que sumado a la venta sin receta médica de antimicrobianos ${ }^{(35,36)}$ conlleva a problemas adicionales en la pandemia, como el desabastecimiento temporal de estos fármacos ${ }^{(37)}$ y hospitalizaciones por efectos adversos.

En la tabla 1 se aprecia el perfil de interacciones entre estos fármacos y las consideraciones especiales en ciertos escenarios, basados en el perfil farmacocinético y farmacodinámico de cada una de las drogas, para su consideración en la práctica clínica diaria.

\section{USO EMPÍRICO DE LOS ANTIMICROBIANOS EN COVID-19 Y SU POSIBLE ROL EN LA TORMENTA DE CITOQUINAS Y SEPSIS}

En ausencia de coinfección bacteriana, la administración 
empírica de antimicrobianos podría conducir a una tormenta inflamatoria a través de dos rutas. La ruta directa ocurre a través de la interleucina $1 B, \mathrm{IL}-6$ y factor de necrosis tumoral a (TNF-a) o por inducción de expresión de receptores Toll-like (TLR) ${ }^{(38)}$.

Se ha demostrado que una sola dosis de ceftazidima puede liberar IL-6 y TNF-a en ausencia de infección (39). A su vez, algunos betalactámicos, como piperacilina, pueden inducir la expresión de TLR, principalmente TLR-4, que es mediador en la liberación de IL-1 e IL-6 (rol crítico en tormenta de citoquinas) en monocitos humanos. Además, se ha descrito que moxifloxacino, doxiciclina y gentamicina también producen sobreexpresión de IL-1 ${ }^{(40)}$.

La ruta indirecta ocurre a través del incremento de endotoxinas intestinales o endotoxemia (como ciprofloxacino oral, tobramicina/polimixina). La sobrexpresión de TLR-4 y la endotoxemia pueden desencadenar la cascada inflamatoria de citoquinas a través de la activación del factor nuclear kappa- $B$ (NF-KB), principal regulador de sepsis y shock séptico ${ }^{(38)}$.

La información actual es insuficiente para explicar la fisiopatología de la sepsis y el choque séptico en pacientes con COVID-19, por lo que se recomienda que el uso empírico de antimicrobianos con capacidad inflamatoria debe ser racional en vista de que un porcentaje significativo de pacientes fallecidos con COVID-19 presenta sepsis o choque séptico ${ }^{(4)}$.

\section{SUPERINFECCIONES EN COVID-19}

La enfermedad por SARS-CoV-2 predispone al desarrollo de superinfecciones a través de dos posibles mecanismos no excluyentes entre sí: la disregulación del sistema inmune del huésped y el estado proinflamatorio secundario a formas severas de COVID-19, con la consiguiente proliferación de bacterias (que implica la alteración del balance de poblaciones dentro del microbioma y el sobrecrecimiento de especies no susceptibles) y hongos. El virus facilita la colonización y fijación de bacterias al tejido del huésped, lo que resulta en mayor daño tisular, posibilidad de sepsis y perturbación en la homeostasis intestinal ${ }^{(41)}$. En los pacientes hospitalizados existe un mayor riesgo de adquirir infecciones intrahospitalarias, principalmente en aquellos que están críticamente enfermos o con necesidad de procedimientos o terapias invasivas, por ejemplo, ventilación mecánica, independientemente de los casos de COVID-19 ${ }^{(42)}$.

No hay investigaciones sobre el impacto clínico de las superinfecciones asociadas a COVID-19. A la fecha, la información disponible es variable debido a múltiples razones, desde el poco interés inicial en estas complicaciones durante la epidemia, la restricción para realizar estudios diagnósticos por el potencial riesgo de generar aerosoles, la sobrecarga laboral y el riesgo de exposición del personal de salud, hasta problemas metodológicos en los artículos, como falta de mención, diversidad de definiciones de caso (algunos estudios consideran solo procalcitonina $\geq 0,5 \mathrm{ng} / \mathrm{mL}$, mientras que otros usan el criterio clínico y aislamiento microbiológico para el diagnóstico de infección secundaria), falta de seguimiento posterior o dificultad para distinguir entre infección y colonización en pacientes críticos ${ }^{(42)}$.

La prevalencia de infecciones secundarias bacterianas y fúngicas es variable, oscila entre $0 \%$ en Seattle ${ }^{(43)}$, 5-27\% en China ${ }^{(44,45)}$ y $50 \%$ dentro del subgrupo de los no sobrevivientes ${ }^{(4,46)}$, lo que sugiere una probable e importante contribución en la mortalidad de estos pacientes. Las diferencias entre hospitales pueden explicarse, además de lo ya mencionado, por las medidas de prevención utilizadas ${ }^{(42)}$ y la buena adherencia a las guías de práctica clínica o efectividad de los PROA.

Las superinfecciones se presentan a partir de la segunda semana después de la admisión en $\mathrm{UCl}$, y con frecuencia son eventos terminales en la evolución de la enfermedad. Las neumonías intrahospitalarias/neumonía asociada a ventilación mecánica (NIH/NAV) e infecciones del torrente sanguíneo fueron las principales complicaciones infecciosas observadas causadas por bacilos gramnegativos multirresistentes (Acinetobacter baumannii, Klebsiella pneumoniae BLEE, Klebsiella pneumoniae resistente a carbapenémicos, Pseudomonas aeruginosa, Enterobacter cloacae, Serratia marcescens), Aspergillus spp. y Candida spp. ${ }^{(42)}$. De estas, el diagnóstico de aspergilosis pulmonar asociada a COVID-19 (APAC) es un reto, pues la mayoría de pacientes críticos pueden no tener un factor de riesgo correctamente identificado (neutropenia $<500 \mathrm{~mm}^{3}$ antes o al ingreso a $\mathrm{UCl}$, inmunodeficiencia adquirida) ${ }^{(47)}$, además de las limitaciones diagnósticas para documentar la presencia de Aspergillus en cultivos del tracto respiratorio inferior ${ }^{(48)}$.

Las terapias inmunomoduladoras (corticoides) o biológicas, cuyo blanco son algunas citoquinas como IL-1B, IL-6 y TNFa, pueden incrementar el riesgo de superinfecciones bacterianas. Existe evidencia clínica de que las dosis altas de corticoides incrementan el riesgo de superinfecciones en pacientes con SDRA ${ }^{(41)} \mathrm{y}$, recientemente, se vienen reportando infecciones en pacientes que utilizan tocilizumab para COVID-19 hasta en $13 \%$ de los casos ${ }^{(49)}$. Aun así, es necesario evaluar estos riesgos en estudios randomizados.

Es importante considerar que el deterioro secundario en 
Uso racional de antimicrobianos en tiempos de COVID-19 en Perú: rol de los programas de optimización del uso de antimicrobianos e intervenciones desde el punto de vista de control de infecciones

los días 7 al 9 puede atribuirse a la fase inflamatoria (fase adaptativa inmune) en vez de a una superinfección ${ }^{(50)}$, donde se pueden encontrar manifestaciones de tormenta de citoquinas como falla cardiaca (miocarditis), embolismo pulmonar (eventos trombóticos) o sobrecarga de fluidos ${ }^{(51)}$.

Tabla 1. Interacciones de los antimicrobianos recomendados como parte del esquema de manejo de casos leves por COVID-19 en Perú y dosis en escenarios especiales

\begin{tabular}{|c|c|c|}
\hline $\begin{array}{c}\text { Antimicrobiano } \\
\text { Índice PK/PD } \\
\text { AUC }\end{array}$ & Interacciones & $\begin{array}{c}\text { Consideraciones para administración } \\
\text { en escenarios especiales }\end{array}$ \\
\hline $\begin{array}{c}\text { Azitromicina }{ }^{(52)} \\
\text { índice PK-PD: AUC/MIC } 24 \text { h } \\
\text { AUC (ug*hr/mL) } \\
4,3(500 \mathrm{mg} \mathrm{VO/día)} \\
20 \text { (2 gr VO/día) } \\
9,6 \text { (AUC }_{24} \text { pre steady state) }\end{array}$ & 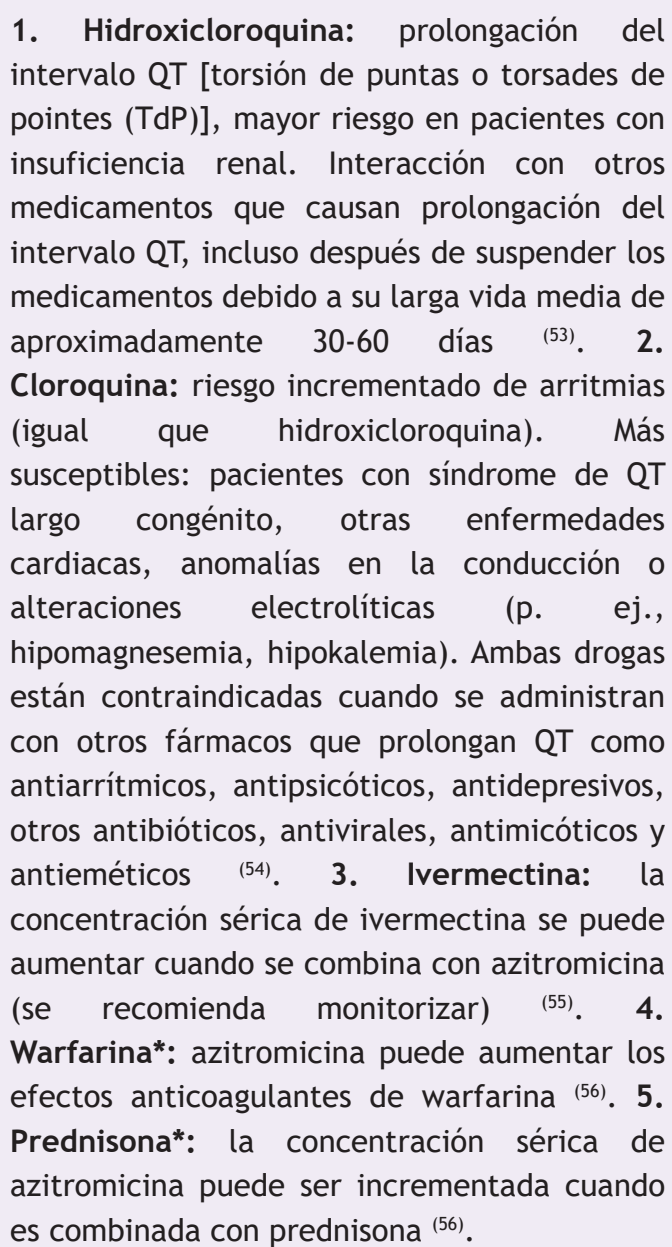 & $\begin{array}{l}\text { Gestación: categoría B. Se han } \\
\text { realizado estudios de reproducción en } \\
\text { ratas y ratones a dosis tóxicas ( } 2-4 \\
\text { veces en humanos). En este momento, } \\
\text { no hay estudios concluyentes y bien } \\
\text { controlados que se hayan realizado en } \\
\text { mujeres embarazadas. Dado que los } \\
\text { estudios de reproducción en animales } \\
\text { no siempre predicen la respuesta en } \\
\text { humanos, azitromicina debe utilizarse } \\
\text { durante el embarazo solo si es } \\
\text { claramente necesaria } \\
\text { Hemodiálisis: no es necesario ajustar } \\
\text { la dosis. Cirróticos: no es necesario } \\
\text { modificar la dosis de azitromicina, a } \\
\text { pesar de su metabolismo hepático }{ }^{(52)} \text {. }\end{array}$ \\
\hline
\end{tabular}




\begin{tabular}{|c|c|c|}
\hline $\begin{array}{c}\text { Antimicrobiano } \\
\text { Índice PK/PD } \\
\text { AUC }\end{array}$ & Interacciones & $\begin{array}{c}\text { Consideraciones para administración } \\
\text { en escenarios especiales }\end{array}$ \\
\hline $\begin{array}{c}\text { Doxiciclina }{ }^{(52)} \\
\text { índice PK-PD: AUC/MIC } 24 \mathrm{~h} \\
\text { AUC (ug*hr/mL) } \\
31,7 \\
\mathrm{AUC}_{0 \text {-infinito }} \\
\text { (100 mg } 1 \text { dosis) }\end{array}$ & $\begin{array}{l}\text { 1. Hidroxicloroquina: sin interacciones }{ }^{(57)} \text {. } \\
\text { 2.Cloroquina: doxiciclina puede disminuir la } \\
\text { tasa de excreción de cloroquina, lo que podría } \\
\text { dar como resultado un nivel sérico más alto }{ }^{(57)} \text {. } \\
\text { Ivermectina: sin interacciones } \\
\text { 3. Warfarina*: doxiciclina puede aumentar los } \\
\text { efectos anticoagulantes de warfarina en algunos } \\
\text { pacientes, y el riesgo de hemorragia }{ }^{(57)} \text {. } \\
\text { 4.Prednisona*: doxiciclina puede disminuir la } \\
\text { tasa de excreción de prednisona, lo que podría } \\
\text { dar como resultado un nivel sérico más alto }{ }^{(57)} \text {. }\end{array}$ & $\begin{array}{l}\text { Gestación: categoría D }{ }^{(52)} \text {. Los } \\
\text { resultados procedentes de estudios en } \\
\text { animales indican que las tetraciclinas } \\
\text { atraviesan la placenta, aparecen en } \\
\text { tejidos fetales y pueden tener efectos } \\
\text { tóxicos sobre el desarrollo del feto (a } \\
\text { menudo se relacionan con el retraso en } \\
\text { el desarrollo del esqueleto) }{ }^{(57)} \text {. } \\
\text { Hemodiálisis: mantener dosis } \\
\text { convencional }{ }^{(52)} \text {. Cirróticos: no es } \\
\text { necesario ajustar dosis }{ }^{(52)} \text {. }\end{array}$ \\
\hline $\begin{array}{c}\text { Ivermectina }{ }^{(52)} \\
\text { Índice PK-PD: no datos } \\
\text { AUC (ug*hr/mL) } \\
\text { no datos }\end{array}$ & $\begin{array}{l}\text { 1.Azitromicina: la concentración sérica de } \\
\text { ivermectina puede aumentar cuando se } \\
\text { combina con azitromicina (monitorizar) }{ }^{(55)} \text {. } \\
\text { 2. Doxiciclina: sin interacciones }{ }^{(58)} \text {. } \\
\text { 3. Warfarina*: ivermectina puede aumentar } \\
\text { los efectos anticoagulantes de warfarina en } \\
\text { algunos pacientes }{ }^{(58)} \text {. 4.Prednisona*: sin } \\
\text { interacciones }{ }^{(58)} \text {. }\end{array}$ & 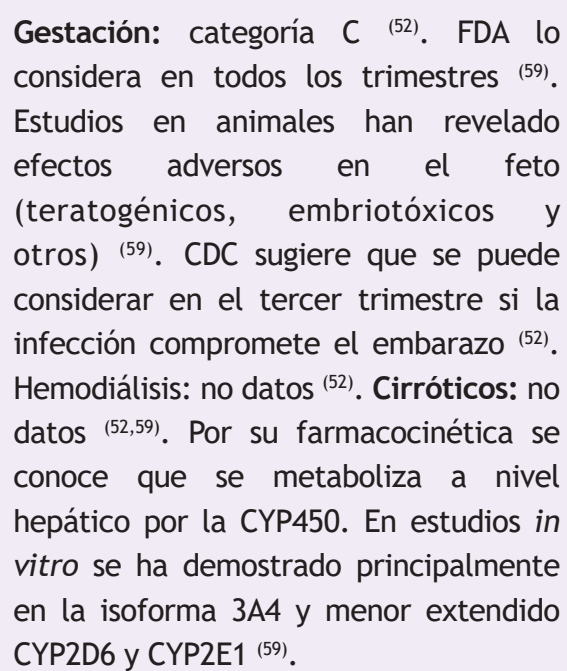 \\
\hline
\end{tabular}

PK/PD = farmacocinética/farmacodinamia, $A U C$ = área bajo la curva, CIM = concentración inhibitoria mínima, steady state = estado estacionario, VO = vía oral. "Drogas recomendadas en campañas de "infodemia": warfarina, prednisona. FDA $=$ Food and Drug Administration $\mathrm{CDC}=$ Centers for Disease Control and Prevention 
Uso racional de antimicrobianos en tiempos de COVID-19 en Perú: rol de los

programas de optimización del uso de antimicrobianos e intervenciones desde el

punto de vista de control de infecciones

ROL DE LOS PROGRAMAS DE OPTIMIZACIÓN DE USO DE ANTIMICROBIANOS EN LA RESPUESTA FRENTE A COVID-19

Actualmente, en Perú, el plan multisectorial para enfrentar la resistencia a los antimicrobianos 2019-2021 considera, dentro de sus objetivos, la implementación a nivel nacional de los PROA ${ }^{(60)}$, aun sin recomendaciones específicas ni estrategias diseñadas en una norma nacional. A pesar de ello, ya se han reportado metas producto de la implementación de los PROA en algunos hospitales locales, como la reducción del consumo de antimicrobianos como ceftriaxona, imipenem o vancomicina, cuyo potencial efecto es la presión de selección para la aparición de gérmenes multirresistentes. Estos antimicrobianos forman parte del tratamiento usado en algunos pacientes hospitalizados por COVID-19, lo cual obliga a plantear medidas efectivas para monitorizar su consumo, por ejemplo, el uso de indicadores como días de tratamiento (DOT) o dosis diarias definidas (DDD) ${ }^{(6)}$.

En circunstancias normales, los objetivos de los PROA en Latinoamérica se convierten en un desafío al tratar de lograr un cambio de comportamiento en los prescriptores de antimicrobianos. En entornos de recursos limitados, se suman la escasez de recursos humanos, la falta de financiamiento, la organización interna y la infraestructura inadecuada de los hospitales ${ }^{(61)}$. En Perú, la actual pandemia está dificultando el manejo de enfermedades crónicas y la prestación de atención aguda para enfermedades no relacionadas con COVID-19 ${ }^{(62)}$, incluidas las infecciones bacterianas agudas. El efecto local, donde la provisión de atención médica es limitada, probablemente, sea peor que en otros países. En ambos entornos, el impacto de los PROA puede ser significativo.

La meta principal de los PROA en Perú debe ser promover que los antimicrobianos no se empleen de forma imprudente o precipitada como tratamiento empírico o para prevención de infecciones virales, tanto en hospitalización o en la comunidad (uso empírico en todos los casos). La mayoría de pacientes con COVID-19 tiene evolución autolimitada ${ }^{(63)}$, por lo que, en general, los antimicrobianos son innecesarios. En aquellos que requieran hospitalización, la evaluación clínica correcta para diferenciar entre infección bacteriana y viral se convierte en otro desafío, pues los pacientes presentan fiebre, hipoxia, elevación de proteína C-reactiva (PCR), características que son indicadores razonables para sospechar de una infección bacteriana (64). Es así que la medición de PCR puede ser un marcador con bajo valor discriminatorio de infección bacteriana en COVID-19 (igualmente, en influenza). Si bien es cierto que la procalcitonina es ampliamente utilizada (sobre todo, en $\mathrm{UCl}$ ), puede estar elevada en neumonía severa por SARS-CoV-2, por lo que su utilidad deberá ser evaluada prospectivamente ${ }^{(65)}$.
Junto con las dificultades observadas en las experiencias locales de los PROA, destacan la falta de métodos diagnósticos microbiológicos rápidos de patógenos concomitantes (como los paneles moleculares multipatógenos) y la identificación de mecanismos de resistencia en entornos de alta prevalencia como el nuestro, pues son la herramienta esencial de estos programas (diagnostic stewardship) (66). Esto impide descartar coinfecciones en la mayoría de unidades de urgencias que atienden pacientes con COVID-19, además de las limitaciones para obtener muestras de lavado bronquio alveolar ${ }^{(67)}$.

En ausencia de un tratamiento antiviral, decidir qué antimicrobianos serán beneficiosos es una pieza clave. Al parecer, a diferencia de la experiencia con la influenza, las coinfecciones bacterianas en COVID-19 son infrecuentes ${ }^{(68,69)}$. Sin embargo, en la ciudad de Wuhan, cuando la pandemia inició, la mayoría de pacientes recibió antimicrobianos, sobre todo quinolonas respiratorias, a pesar de que las guías chinas no recomendaban el uso de antimicrobianos de amplio espectro (70). En Perú, probablemente exista una heterogeneidad en las prescripciones de antimicrobianos frente a la sospecha de neumonía de la comunidad y COVID-19, sumado a la baja adherencia a guías de práctica clínica, según datos previos obtenidos en enfermedades de las vías respiratorias bajas ${ }^{(71)}$.

Otros factores adicionales para la prescripción incorrecta de antimicrobianos son la ansiedad por no disponer de fármacos antivirales con eficacia probada, la alta carga laboral y los altos niveles de estrés del personal médico. Todo ello contribuye al incumplimiento de las guías ${ }^{(51,72)}$.

La resistencia antimicrobiana local documentada en tres hospitales de la seguridad social de Lima ( $E$. coli y $K$. pneumoniae BLEE $54 \%$ y $64 \%$, en servicios de hospitalización y emergencias, respectivamente; Pseudomonas aeruginosa y $A$. baumannii resistente a carbapenémicos hasta > $65 \%$ y $>85 \%$, en unidades de cuidados intensivos, respectivamente y $S$. aureus resistente a meticilina $>45 \%$ en emergencias) ${ }^{(6)}$, por ejemplo, puede incrementarse debido a la diseminación de estos patógenos intra e inter instituciones, dado que en la práctica diaria, al centrarse en un solo agente patógeno (SARS-CoV-2), se afecta la capacidad de muestreo de otras bacterias y se relajan las medidas de prevención y control de infecciones (73). Además, los equipos de PROA redistribuidos por temas de contingencia y la capacidad disminuida de laboratorio por deserción del personal son agravantes en la dinámica de trabajo previa ${ }^{(74)}$.

En la tabla 2 se resumen algunas recomendaciones de las posibles estrategias a adoptar por los PROA locales en 
la pandemia de la COVID-19 basados en experiencias o recomendaciones encontradas en la literatura ${ }^{(51,75-81)}$.

El desescalamiento, suspensión de antimicrobianos y la evaluación de la duración de días de tratamiento (en el caso de superinfecciones), basados en ausencia de resultados oportunos de cultivos o paneles moleculares, tendrían que guiarse por niveles séricos de procalcitonina ${ }^{(65)}$ y el juicio clínico. Sin embargo, dada la baja frecuencia de superinfecciones, el objetivo principal debe ser la contención del uso empírico de antimicrobianos irreflexivamente desde el ingreso a hospitalización.

Existen áreas potenciales de investigación, como establecer la prevalencia de coinfección bacteriana o viral y de superinfecciones, la evaluación de la utilidad de biomarcadores para descarte de superinfección bacteriana, la evaluación de la contribución de la infección por SARS-CoV-2 versus respuesta inmune en las diferentes fases de la COVID-19 y la evaluación del impacto de la pandemia sobre el uso de antibióticos y la resistencia en centros geriátricos, comunidad y hospitales ${ }^{(51)}$.

Tabla 2. Recomendaciones de los programas de optimización de uso de antimicrobianos (PROA) en la pandemia de COVID-19 que pueden aplicarse en Perú

Grupo de trabajo o autor

Scottish

Antimicrobial

Prescribing Group (SAPG) (75)
Estrategias generales

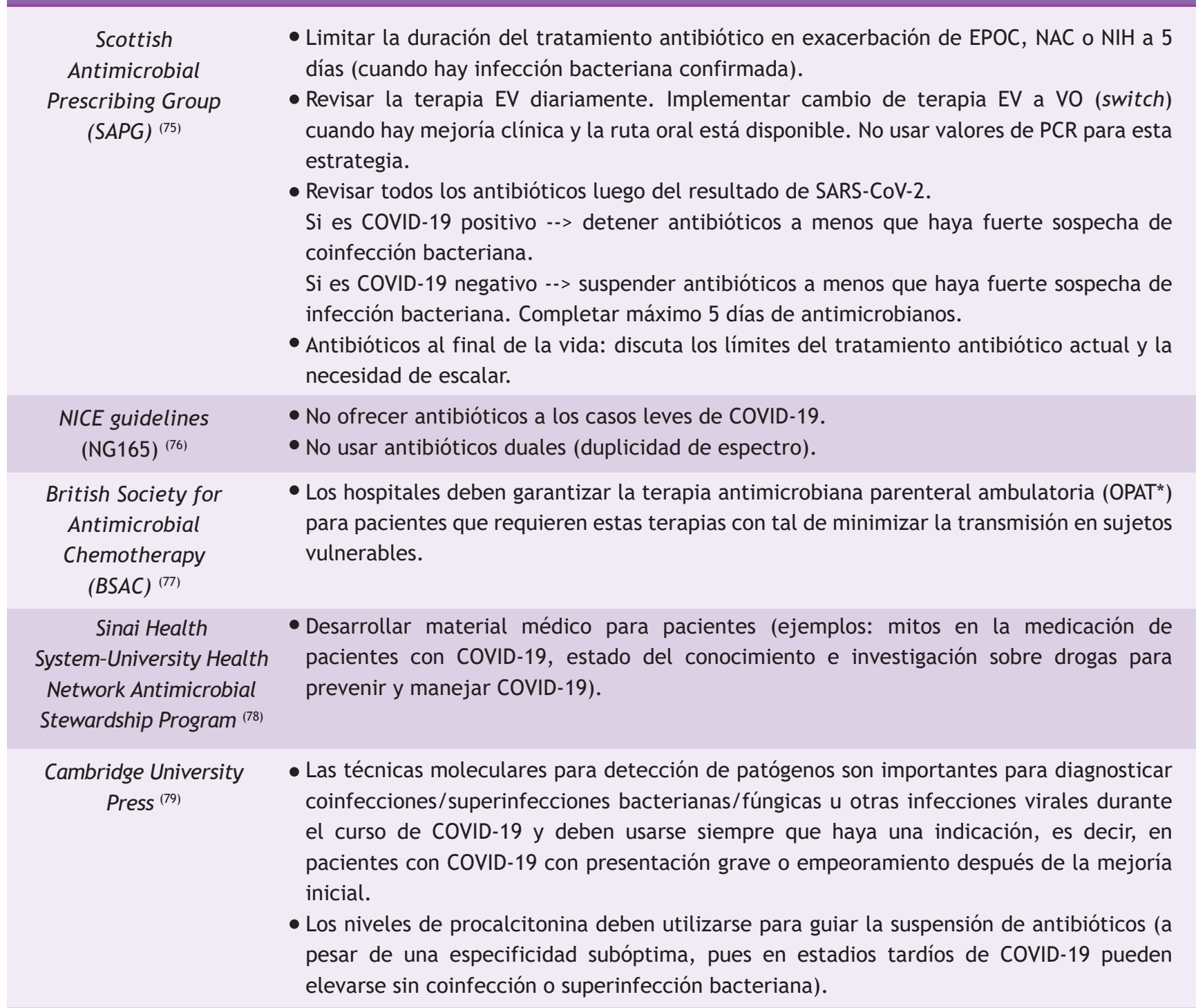


Uso racional de antimicrobianos en tiempos de COVID-19 en Perú: rol de los programas de optimización del uso de antimicrobianos e intervenciones desde el punto de vista de control de infecciones

Grupo de trabajo o autor

Opinión sobre la prevención y el tratamiento de pacientes en riesgo de formas graves de COVID-19, así como la priorización de las pruebas de diagnóstico. (Haut Conseil de la santé publique) ${ }^{\left({ }^{(0)}\right.}$

\section{Estrategias generales}

- Superinfecciones bacterianas y fúngicas: no hay datos locales de superinfecciones, se deben interpretar acorde al perfil de resistencia bacteriana/fúngica local. Los datos de China demuestran alta incidencia de superinfecciones fúngicas que pueden ser comparados con influenza (Aspergillus), y deben alertarnos a realizar el screening de estos patógenos en pacientes críticos.

- Pacientes con enfermedad severa en UCI:

Tratamiento antibiótico

En el caso de neumonía, es necesario tomar cultivos de tracto respiratorio inferior de manera oportuna (virológico, bacteriano y micológico) para documentar las coinfecciones posibles.

Con respecto a la terapia antibiótica inicial:

- Para neumonía intrahospitalaria: seguir recomendaciones específicas acorde a los algoritmos locales.

Surviving Sepsis

Campaign Management

of Critically IIl Adults

With Coronavirus Disease 2019 (COVID-19) ${ }^{(81)}$

COVID-19: don't neglect antimicrobial stewardship principles! Huttner B et al. ${ }^{(51)}$
- En pacientes con ventilación mecánica con COVID-19 y falla respiratoria, se sugiere uso de antibióticos versus no uso (recomendación débil, baja calidad de evidencia).

- Observación: si el equipo tratante inicia con antibióticos empíricos, deben evaluar diariamente desescalar y reevaluar la duración de la terapia y el espectro de actividad basado en los resultados de microbiología y el estado clínico del paciente.

- Los macrólidos y quinolonas deben ser evitados por sus efectos cardiacos (sobre todo en lugares donde se utilizan hidroxicloroquina o lopinavir/ritonavir, a pesar de la evidencia limitada de su eficacia) e impacto sobre la resistencia a los antimicrobianos.

- Los antibióticos no deben ser administrados "profilácticamente" para prevenir neumonía bacteriana.

- Tener presente la posibilidad de otras infecciones (infección tracto urinario, infección de piel y partes blandas, infecciones intraabdominales, etc.) para considerarlas como diagnósticos diferenciales (especialmente en el anciano) y manejarlas de acuerdo a protocolos locales. La sospecha de COVID-19 no debe retrasar el adecuado manejo de estos pacientes.

\footnotetext{
* $E P O C=$ enfermedad pulmonar obstructiva crónica, NAC = neumonía adquirida en la comunidad, NIH = neumonía intrahospitalaria, $\mathrm{EV}=$ endovenoso, $\mathrm{VO}=$ vía oral, $\mathrm{PCR}=$ proteína $\mathrm{C}$-reactiva, $\mathrm{OPAT}=$ Outpatient parenteral antimicrobial therapy, $\mathrm{UCI}=$ unidad de cuidados intensivos, NICE = The National Institute for Health and Care Excellence, SARS-CoV-2: severe acute respiratory syndrome coronavirus 2
}

INTERVENCIONES ADICIONALES EN EL CONTROL DE INFECCIONES DURANTE LA PANDEMIA DE COVID-19 QUE PUEDEN SER ADOPTADAS POR LOS PROGRAMAS DE PREVENCIÓN Y CONTROL DE INFECCIONES (PPCI) EN PERÚ

Transmisión nosocomial de COVID-19

La transmisión nosocomial del SARS-CoV-2 es otro punto preocupante. El metaanálisis realizado por Qi Zhou et al. mostró una incidencia de infecciones nosocomiales de COVID-19 de $44 \%$. De los pacientes confirmados, $33 \%$ fueron médicos (IC $95 \%$ : 0,27-0,40) y solo $2 \%$ no fueron personal de salud (visitantes, otros pacientes hospitalizados, etc.) (IC $95 \%$ : 0,01-0,03) ${ }^{(82)}$.

Sin embargo, dadas las condiciones de la pandemia actual en Perú, donde existe transmisión comunitaria y, posiblemente, escasa proporción de prácticas de prevención adecuadas por los trabajadores de salud en epidemias, basadas en algunas experiencias locales previas de la epidemia de influenza A $\mathrm{H} 1 \mathrm{~N} 1{ }^{(83)}$, es razonable que los médicos puedan ser víctimas y transmisores de SARS-CoV-2 para los pacientes hospitalizados 
por otros motivos. En la tabla 3 se presenta el resumen de recomendaciones internacionales e intervenciones para prevenir la transmisión nosocomial de COVID-19 que pueden ser adaptadas al contexto local.

Tabla 3. Resumen de las intervenciones adicionales para el control de infecciones en la pandemia de COVID-19 que pueden ser adaptadas por los programas de prevención y control de infecciones (PPCI) en Perú

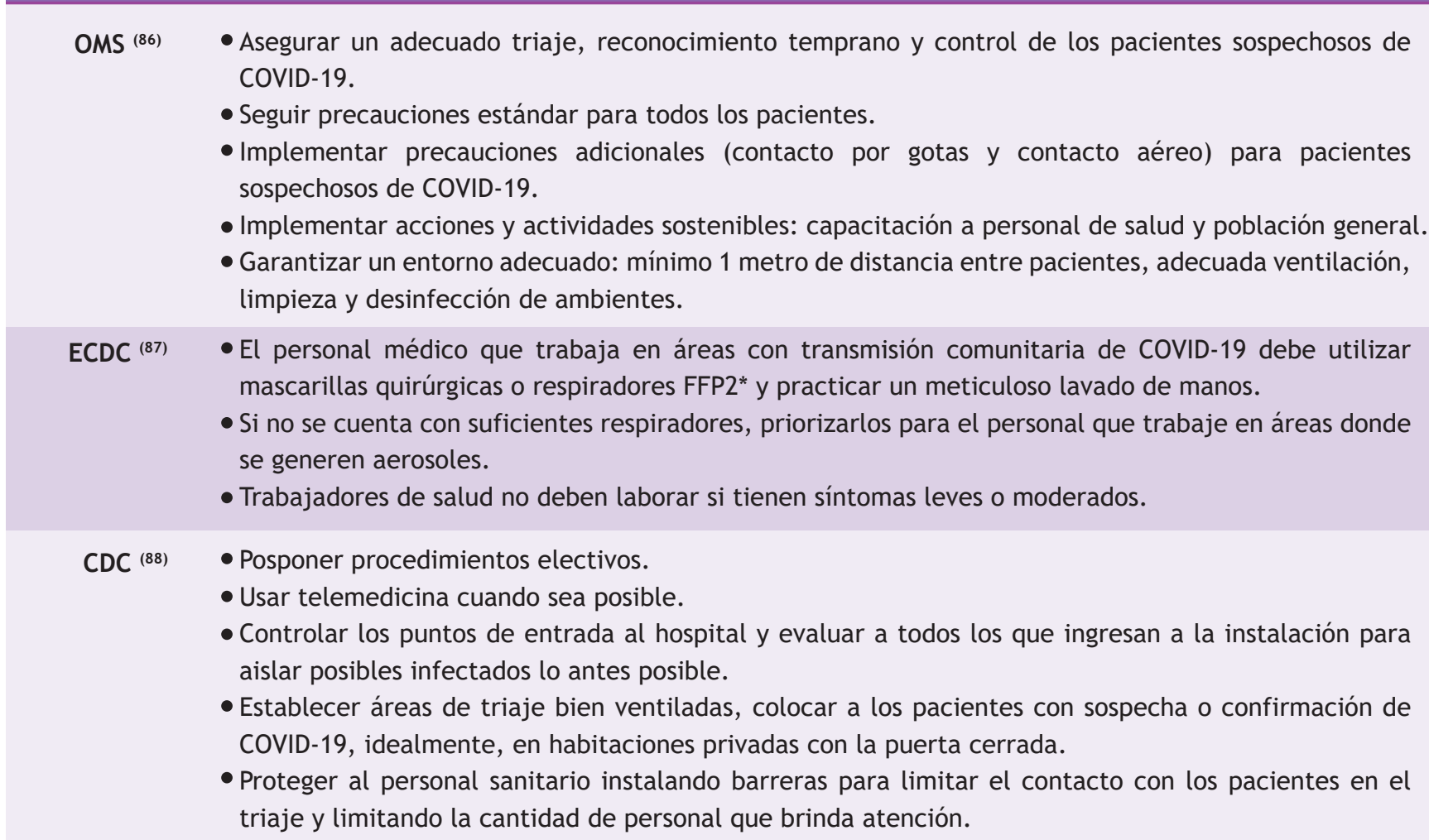

Vacunación antiinfluenza
- Ante la posibilidad de coexistencia de un brote concomitante de SARS-CoV-2 e influenza, la vacunación antiinfluenza es cardinal y reduce el impacto de esta infección, por lo que un aumento de los programas de vacunación podría ser un factor crítico para su prevención (p. ej., seguir una programación estratégica para evitar aglomeraciones) ${ }^{(89)}$.

- Es efectiva en la protección de los trabajadores de salud ${ }^{(90)}$, por lo que administrarla en este grupo de riesgo es también una estrategia esencial para reducir el ausentismo laboral, la cadena de contagios y mantener la fuerza laboral sanitaria.

Vacuna - Optimización de la cobertura de vacunación infantil y su administración creciente en adultos para antineumococo mitigar los efectos de este microorganismo en la lucha contra la pandemia de SARS-CoV-2 (91) bajo medidas estratégicas.

OMS = Organización Mundial de la Salud, ECDC = European Centre for Disease Prevention and Control, CDC = Centers for Disease Control and Prevention, SARS-CoV-2: severe acute respiratory syndrome coronavirus 2 *Su equivalente local sería el respirador N95. 
Uso racional de antimicrobianos en tiempos de COVID-19 en Perú: rol de los

programas de optimización del uso de antimicrobianos e intervenciones desde el

punto de vista de control de infecciones

\section{SITUACIÓN DE LA VACUNACIÓN DURANTE PANDEMIA POR COVID-19}

La inmunización es un servicio básico de salud que debe priorizarse para la prevención de enfermedades transmisibles, y se debe tratar de salvaguardar su continuidad durante la pandemia del COVID-19, mientras sea factible.

Las estrategias de administración de vacunas deben adaptarse y llevarse a cabo en condiciones seguras, y evitar perjuicios frente a trabajadores de la salud y a la comunidad. Según recomendaciones de la OMS ${ }^{(84)}$, la consideración de las opciones de inmunización durante la pandemia de COVID-19 debe guiarse por una evaluación detallada de:

\section{Riesgos epidemiológicos de enfermedades inmunoprevenibles en población general y grupos de riesgo específicos (pacientes hospitalizados, centros de cuarentena temporal). \\ 2.Situación epidemiológica de COVID-19 y medidas de contención relacionadas ya establecidas. \\ 3. Características y limitaciones del sistema de salud y de los servicios de inmunización. \\ 4. Relevancia de la vacuna y la logística necesaria.}

El impacto y la idoneidad de las vacunas elegidas para su colocación en Perú deberían ser monitorizados y reevaluados periódicamente a medida que evoluciona la situación de la COVID-19. En el hemisferio sur durante la época de invierno, la transmisión de otros virus respiratorios puede incrementarse, por lo que se espera que otras vacunas puedan reducir un impacto adicional de otras enfermedades inmunoprevenibles en la pandemia ${ }^{(85)}$.

\section{CONCLUSIONES}

Antes del advenimiento de la pandemia por SARS-CoV-2, en el mundo y en nuestro país ya enfrentábamos una epidemia creciente: la resistencia antimicrobiana. A pesar de la baja tasa de coinfecciones asociadas a COVID-19, el uso empírico de antimicrobianos para su tratamiento y/o prevención es irracional e indiscriminado en el Perú. Las repercusiones a corto plazo son su desabastecimiento y efectos adversos no reportados a los centros de farmacovigilancia. A largo plazo, existe la posibilidad de perder por completo la utilidad de muchos de estos antimicrobianos para el tratamiento de otras infecciones en la comunidad o en el hospital. En esta revisión se han resumido diversas estrategias que pueden ser útiles en tiempos de pandemia y que deben ser adaptadas por los PROA y los equipos de prevención y control de infecciones locales. Sin embargo, surge la importancia de empoderar a estos programas a través de una norma nacional, para que su participación sea activa en la toma de decisiones y aprobación de lineamientos locales.
Contribuciones de autoría: Giancarlo Pérez Lazo se encargó del diseño, concepción del manuscrito, recopilación de fuentes bibliográficas, edición y revisión crítica. Fernando Soto Febres, Adriana Morales Moreno, John Cabrera Enríquez, Janett Díaz Agudo, Rocío Rojas Tovar se encargaron de la recopilación de fuentes bibliográficas y revisión. Berenice Arenas Ramírez y Ricardo Illescas Mucha se encargaron de la recopilación de fuentes bibliográficas y revisión final crítica del artículo. Todos los autores aprobaron la versión final del manuscrito.

Fuentes de financiamiento: El artículo ha sido financiado por los autores.

Conflictos de interés: Los autores declaran no tener ningún conflicto de interés.

\section{REFERENCIAS BIBLIOGRÁFICAS}

1. Ministerio de Salud del Perú. Documento Tecnico: Prevención y Atención de personas afectadas por COVID-19 en el Perú [Internet]. 2020. Disponible en: https://cdn.www.gob.pe/uploads/document/ file/694719/RM_270-2020-MINSA.PDF

2. Sociedad Peruana de Medicina Intensiva. Propuesta en base a consideración de manejo de COVID - 19 emitido por la Sociedad Peruana de Enfermedades Infecciosas y Tropicales (SPEIT) revisada y consensuada con la Sociedad Peruana de Medicina Intensiva (SOPEMI), Sociedad Peruana de Medicina [Internet]. 2020. Disponible en: https://www.sopemi.org.pe/sites/default/files/ Propuesta\%20Sociedades\%20manejo\%20clinico\%20COVID\%20-19\%20 SPEIT\%20\%E2\%80\%93\%20SOPEMI\%20-\%20SPMI\%20-\%20SPN\%20- \%202403-2020\%20version\%20final\%201.1\%20\%281\%29.pdf

3. Acosta G, Escobar G, Bernaola G, Alfaro J, Taype W, Marcos C, et al. Caracterización de pacientes con COVID-19 grave atendidos en un hospital de referencia nacional del Perú. Rev Peru Med Exp Salud Publica. 2020; 37(2): 253-8.

4. Zhou F, Yu T, Du R, Fan G, Liu Y, Liu Z, et al. Clinical course and risk factors for mortality of adult inpatients with COVID-19 in Wuhan, China: a retrospective cohort study. Lancet. 2020; 395(10229): 1054-62.

5. Stevens MP, Patel PK, Nori P. Involving antimicrobial stewardship programs in COVID-19 response efforts: all hands on deck. Infect Control Hosp Epidemiol. 2020; 41(6): 744-5.

6. Hernández-Gómez C, Hercilla L, Mendo F, Pérez-Lazo G, Contreras $E$, Ramírez E, et al. Programas de optimización del uso de antimicrobianos en Perú: Un acuerdo sobre lo fundamental. Rev Chil Infectol. 2019; 36(5): 565-75.

7. Joint commission joins white house effort to reduce antibiotic overuse. Jt Comm Perspect. 2015; 35(7): 4-11.

8. Metlay JP, Waterer GW, Long AC, Anzueto A, Brozek J, Crothers K, et al. Diagnosis and treatment of adults with community-acquired pneumonia. An Official Clinical Practice Guideline of the American Thoracic Society and Infectious Diseases Society of America. Am J Respir Crit Care Med. 2019; 200(7): e45-67.

9. Gautret P, Lagier J-C, Parola P, Hoang VT, Meddeb L, Mailhe M, et al. Hydroxychloroquine and azithromycin as a treatment of COVID-19: results of an open-label non-randomized clinical trial. Int J Antimicrob Agents. 2020; 105949.

10. National Institutes of Health $(\mathrm{NIH})$. Coronavirus Disease 2019 
(COVID-19) Treatment Guidelines [Internet]. 2020. Disponible en: https://covid19treatmentguidelines.nih.gov/.

11. Gérard A, Romani S, Fresse A, Viard D, Parassol N, Granvuillemin $A$, et al. "Off-label" use of hydroxychloroquine , azithromycin lopinavir-ritonavir and chloroquine in COVID-19: A survey of cardiac adverse drug reactions by the French Network of Pharmacovigilance Centers. Therapie. 2020; S0040-5957(20): 30091-3.

12. Bacharier LB, Guilbert TW, Mauger DT, Boehmer S, Beigelman A, Fitzpatrick AM, et al. Early administration of azithromycin and prevention of severe lower respiratory tract illnesses in preschool children with a history of such illnesses a randomized clinical trial. JAMA. 2015; 314(19): 2034-44.

13. Million $M$, Lagier J-C, Gautret $P$, Colson $P$, Fournier P-E, Amrane $S$, et al. Early treatment of COVID-19 patients with hydroxychloroquine and azithromycin: a retrospective analysis of 1061 cases in Marseille, France. Travel Med Infect Dis. 2020; 101738.

14. Cramer CL, Patterson A, Alchakaki A, Soubani AO. Immunomodulatory indications of azithromycin in respiratory disease: a concise review for the clinician. Postgrad Med. 2017; 129(5): 493-9.

15. Kawamura K, Ichikado K, Takaki M, Sakata Y, Yasuda Y, Shingu N, et al. Efficacy of azithromycin in sepsis-associated acute respiratory distress syndrome: a retrospective study and propensity score analysis. Springerplus. 2016; 285(1): 1193.

16. Castro JD, Siccha SM, Egoavil M, Chaparro E, Hernandez R, Silva W, et al. Antibiotic resistance and distribution of serotypes of invasive pneumococcal strains isolated from hospitalized adults in Lima, Peru. Rev Peru Med Exp Salud Publica. 2017; 34(4): 633-41.

17. Khaddour K, Sikora A, Tahir N, Nepomuceno D, Huang T. Case report: the importance of novel Coronavirus Disease (COVID-19) and coinfection with other respiratory pathogens in the current pandemic. Am J Trop Med Hyg. 2020; 102(6): 1208-9.

18. Hong-Rui C, Hao Z, Mei X, Zhen-Bing C, Wan-Xin C. A case of childhood COVID-19 infection with pleural effusion complicated by possible secondary Mycoplasma pneumoniae infection. Pediatr Infect Dis J. 2020.

19. Sodhi $M$, Etminan $M$. Therapeutic potential for tetracyclines in the treatment of COVID-19. Pharmacotherapy. 2020; 40(5): 487-8.

20. Phillips JM, Gallagher T, Weiss SR. Neurovirulent murine coronavirus JHM. SD uses cellular zinc metalloproteases for virus entry and cellcell fusion. J Virol. 2017; 91(8): e01564-16.

21. Rothan HA, Mohamed Z, Paydar M, Rahman NA, Yusof R. Inhibitory effect of doxycycline against dengue virus replication in vitro. Arch Virol. 2014; 159(4): 711-8.

22. Rothan HA, Bahrani H, Mohamed Z, Teoh TC, Shankar EM, Rahman NA, et al. A combination of doxycycline and ribavirin alleviated chikungunya infection. PLoS One. 2015; 10(5): e0126360.

23. Rempe S, Hayden J, Robbins R, Hoyt J. Tetracyclines and pulmonary inflammation. Endocrine, Metab Immune Disord Targets. 2007; 7: 232.

24. U.S. National Library of Medicine. Doxycycline: Clinical Trials.gov [Internet]. 2020. Disponible en: https://clinicaltrials.gov/ct2/ results? recrs=\&cond=SARS-Cov2\&term=doxycycline\&cntry=\&state=\& city=\&dist=

25. Calvo J, Martínez-Martínez L. Mecanismos de acción de los antimicrobianos. Enferm Infecc Microbiol Clin. 2009; 27(1): 44-52.

26. Rawson T, Moore L, Zhu N, Ranganathan N, Skolimowska K, Gilchrist $M$, et al. Bacterial and fungal co-infection in individuals with coronavirus: a rapid review to support COVID-19 antimicrobial prescribing. Clin Infect Dis. 2020; ciaa530.

27. Torres N, Velásquez R, Mercado EH, Egoavil M, Horna G, Mejía L, et al. Resistencia antibiótica de Streptococcus pneumoniae en portadores nasofaríngeos sanos de siete regiones del Perú. Rev Peru Med Exp Salud Publica. 2014; 30(4): 575-82.

28. Valle-Mendoza J, Orellana-Peralta F, Marcelo-Rodríguez A, Verne
E, Esquivel-Vizcarra M, Silva-Caso W, et al. High prevalence of mycoplasma pneumoniae and chlamydia pneumoniae in children with acute respiratory infections from Lima, Peru. PLoS One. 2017; 12(1): e0170787.

29. Caly L, Druce JD, Catton MG, Jans DA, Wagstaff KM. The FDAapproved drug ivermectin inhibits the replication of SARS-CoV-2 in vitro. Antiviral Res. 2020; 178(3): 104787.

30. Momekov G, Momekova D. Ivermectin as a potential COVID-19 treatment from the pharmacokinetic point of view: antiviral levels are not likely attainable with known dosing regimens. Biotechnol Biotechnol Equip. 2020; 34(1): 469-74.

31. U.S.National Library of Medicine. Ivermectin: Clinical Trials.gov [Internet]. 2020. Disponible en: https://clinicaltrials.gov/ct2/resul ts?cond=Covid19\&term=ivermectin\&cntry=\&state=\&city=\&dist=

32. Ministerio de Salud del Perú. Dirección General de Medicamentos, insumos y drogas - DIGEMID: Alerta DIGEMID N 12-2020. Ivermectina: Recomendaciones de uso asociadas a infección por COVID-19 [Internet]. 2020. Disponible en:http://www.digemid.minsa.gob.pe/

33. Orso D, Federici N, Copetti R, Vetrugno L, Bove T. Infodemic and the spread of fake news in the COVID-19-era. Eur J Emerg Med. 2020; 10.

34. Diario La República-Perú. Es falso que la doxiciclina sea un tratamiento alternativo para la COVID-19 [Artículo electrónico]. Publicado 12 mayo 2020. Disponible en: https://larepublica.pe/ verificador/2020/05/12/coronavirus-es-falso-que-la-doxiciclinasea-un-tratamiento-alternativo-para-la-covid-19-minsa-oms/

35. Wirtz VJ, Dreser A, Gonzales R. Trends in antibiotic utilization in eight Latin American countries, 1997-2007. Rev Panam Salud Publica. 2010; 27(3): 219-25.

36. Ecker L, Ruiz J, Vargas M, Del Valle LJ, Ochoa TJ. Prevalence of purchase of antibiotics without prescription and antibiotic recommendation practices for children under five years of age in private pharmacies in Peri-urban areas of Lima, Peru. Rev Peru Med Exp Salud Publica. 2016; 33(2): 215-23.

37. Diario Gestión-Perú. Demanda de medicinas para tratar síntomas de COVID-19 aumentó en cinco veces [Artículo electrónico]. Publicado 14 de mayo 2020. Disponible en: https://gestion.pe/economia/ inkafarma-precios-covid-19-demanda-de-medicinas-para-tratarsintomas-de-covid-19-aumento-en-cinco-veces-noticia/?ref=gesr

38. Hantoushzadeh S, Norooznezhad AH. Inappropriate antibiotic consumption as a possible cause of inflammatory storm and septic shock in patients diagnosed with Coronavirus Disease 2019 (COVID-19). Arch Med Res. 2020; S0188-4409(20): 30409.

39. Alkharfy KM, Kellum JA, Frye RF, Matzke GR. Effect of ceftazidime on systemic cytokine concentrations in rats. Antimicrob Agents Chemother. 2000; 44(11): 3217-9.

40. Bode C, Diedrich B, Muenster S, Hentschel V, Weisheit C, Rommelsheim K, et al. Antibiotics regulate the immune response in both presence and absence of lipopolysaccharide through modulation of Toll-like receptors, cytokine production and phagocytosis in vitro. Int Immunopharmacol. 2014; 18(1): 27-34.

41. Bengoechea JA, Bamford CGG. SARS-CoV-2, bacterial co-infections, and AMR: the deadly trio in COVID-19?. EMBO Mol Med. 2020.

42. Clancy CJ, Nguyen MH. COVID-19, superinfections and antimicrobial development: What can we expect?. Clin Infect Dis. 2020; ciaa524.

43. Bhatraju PK, Ghassemieh BJ, Nichols M, Kim R, Jerome KR, Nalla AK, et al. Covid-19 in critically ill patients in the Seattle region-case series. N Engl J Med. 2020.

44. Chen N, Zhou M, Dong X, Qu J, Gong F, Han Y, et al. Epidemiological and clinical characteristics of 99 cases of 2019 novel coronavirus pneumonia in Wuhan, China: a descriptive study. Lancet. 2020; 395: 507-13.

45. Chen X, Zhao B, Qu Y, Chen Y, Xiong J, Feng Y, et al. Detectable serum SARS-CoV-2 viral load (RNAaemia) is closely correlated with 
Uso racional de antimicrobianos en tiempos de COVID-19 en Perú: rol de los programas de optimización del uso de antimicrobianos e intervenciones desde el punto de vista de control de infecciones

drastically elevated interleukin 6 (IL-6) level in critically ill COVID-19 patients. Clin Infect Dis. 2020; ciaa449.

46. Cao J, Tu WJ, Cheng W, Yu L, Liu YK, Hu X, et al. Clinical features and short-term outcomes of 102 patients with Corona Virus Disease 2019 in Wuhan, China. Clin Infect Dis. 2020; ciaa243.

47. Alanio A, Dellière $S$, Fodil $S$, Bretagne $S$, Mégarbane B. High prevalence of putative invasive pulmonary aspergillosis in critically III COVID-19 patients. Lancet Respir Med. 2020; 8(6): e48-9.

48. Blot SI, Taccone FS, Van den Abeele AM, Bulpa P, Meersseman W, Brusselaers $\mathrm{N}$, et al. A clinical algorithm to diagnose invasive pulmonary aspergillosis in critically ill patients. Am J Respir Crit Care Med. 2012; 186(1): 56-64.

49. Campochiaro C, Della-torre E, Cavalli G, Luca G De, Ripa M, Boffini N, et al. Efficacy and safety of tocilizumab in severe COVID-19 patients: a single-centre retrospective cohort study. Eur J Intern Med. 2020.

50. Xiong $Y$, Sun D, Liu $Y$, Fan $Y$, Zhao L, Li X, et al. Clinical and highresolution CT features of the COVID-19 infection: comparison of the initial and follow-up changes. Invest Radiol. 2020; 55(6): 332-9.

51. Huttner B, Catho G, Pano-Pardo JR, Pulcini C, Schouten J. COVID-19: don't neglect antimicrobial stewardship principles!. Clin Microbiol Infect. 2020; S1198-743X(20): 30232-9.

52. Gilvert DN, editor. Guide Sanford collection 2019: Antimicrobial drugs; Dosing/Use in special population; pharmacology [Internet]. 2020.

53. U.S. Food and Drug Administration. FDA drug safety comunication. FDA cautions against use of hydroxychloroquine or chloroquine for COVID-19 outside of the hospital setting or a clinical trial due to risk of heart rhythm problems [Internet]. 2020. Disponible en: https:// www.fda.gov/drugs/drug-safety-and-availability/fda-cautionsagainst-use-hydroxychloroquine-or-chloroquine-covid-19-outsidehospital-setting-or

54. Escuela Andaluza de Salud Pública. Fármacos que prolongan el intervalo QT. Bol Ter Andaluz. 2017; 32(2).

55. El-Tahtawy A, Glue P, Andrews EN, Mardekian J, Amsden GW, Knirsch CA. The effect of azithromycin on ivermectin pharmacokinetics a population pharmacokinetic model analysis. PLoS Negl Trop Dis. 2008; 2(5): e236.

56. Drugbank. Azithromycin [Internet]. 2020. Disponible en: https:// www.drugbank.ca/drugs/DB00207.

57. Drugbank. Doxycycline [Internet]. 2020. Disponible en: https:// www.drugbank.ca/drugs/DB00254

58. Drugbank. Ivermectin [Internet]. 2020. Disponible en: https://www. drugbank.ca/drugs/DB00602

59. BM MICROMEDEX® Drug Monograph: Ivermectin [Internet]. 2020. Disponible en: https://www.micromedexsolutions.com/

60. Decreto Supremo $N^{\circ}$ 010-2019-SA. Aprobación del Plan Multisectorial para enfrentar la resistencia a los Antimicrobianos 2019-2021 [Internet]. 2020. Disponible en: https://antimicrobianos.ins.gob. pe/images/contenido/plan-nacional/Decreto_Supremo_010-2019SA-C.pdf

61. Cox JA, Vlieghe E, Mendelson M, Wertheim H, Ndegwa L, Villegas MV, et al. Antibiotic stewardship in low- and middle-income countries: the same but different?. Clin Microbiol Infect. 2017; 23(11): 812-8.

62. Gozzer E, Canchihuamán F, Espinoza R. COVID-19 y la necesidad de actuar para mejorar las capacidades del Perú frente a las pandemias. Rev Peru Med Exp Salud Publica. 2020; 37(2).

63. Wu Z, McGoogan JM. Characteristics of and important lessons from the Coronavirus Disease 2019 (COVID-19) outbreak in China. JAMA. 2020.

64. Guan WJ, Ni ZY, Hu Y, Liang WH, Ou CQ, He JX, et al. Clinical characteristics of coronavirus disease 2019 in China. N Engl J Med. 2020; 382: 1708-20.

65. Langford BJ, Beriault D, Schwartz KL, Seah J, Pasic MD, Cirone $\mathrm{R}$, et al. A real-world assessment of procalcitonin combined with antimicrobial stewardship in a community ICU. J Crit Care. 2020; 57: 130-3.

66. Patel R, Fang FC. Diagnostic stewardship: opportunity for a laboratory-infectious diseases partnership. Clin Infect Dis. 2018; 67(5): 799-801.

67. Rodriguez-Morales AJ, Cardona-Ospina JA, Gutiérrez-Ocampo E, Villamizar-Peña R, Holguin-Rivera Y, Escalera-Antezana JP, et al. Clinical, laboratory and imaging features of COVID-19: a systematic review and meta-analysis. Travel Med Infect Dis. 2020; 34: 101623.

68. Shah NS, Greenberg JA, McNulty MC, Gregg KS, Riddell J, Mangino $\mathrm{JE}$, et al. Bacterial and viral co-infections complicating severe influenza: Incidence and impact among 507 U.S. patients, 2013-14. J Clin Virol. 2016; 80: 12-9.

69. Kim D, Quinn J, Pinsky B, Shah NH, Brown I. Rates of co-infection between SARS-CoV-2 and other respiratory pathogens. 2020; 323(20): 2085-6.

70. Zhang J, Zhou L, Yang Y, Peng W, Wang W, Chen X. Therapeutic and triage strategies for 2019 novel coronavirus disease in fever clinics. Lancet Respir Med. 2020; 8(3): e11-2.

71. Avila Quispe VA, Muñoz Díaz EJ. Adherencia a la Guía de Práctica Clínica en la Antibióticoterapia en Pacientes con Neumonía del "Hospital II EsSalud", Cajamarca-2015. Cajamarca: Universidad Privada Antonio Guillermo Urrelo. Facultad de Ciencias de la Salud; 2016.

72. Lai J, Ma S, Wang Y, Cai Z, Hu J, Wei N, et al. Factors associated with mental health outcomes among health care workers exposed to Coronavirus Disease 2019. JAMA. 2020; 3(3): e203976.

73. Pérez-Lazo G, Salazar SA, Ramírez BA, Guillermo N, Irigoyen A. Camino a la bacteria pan-resistente: ¿Es posible la implementación de estrategias para disminuir la diseminación interespecies del gen mcr-1 en Perú?. An Fac Med. 2019; 80(1): 131-2.

74. Rawson TM, Moore LSP, Castro-Sanchez E, Charani E, Davies F, Satta G, et al. COVID-19 and the potential long-term impact on antimicrobial resistance. J Antimicrob Chemother. 2020; dkaa194.

75. Seaton RA, Scottish Antimicrobial Prescribing Group. Advice to Antimicrobial Management Teams (AMTs) on antimicrobial prescribing in suspected lower respiratory tract infections in the context of the COVID-19 pandemic [Internet]. 2020. Disponible en: https://www. sapg.scot/about-us/latest-updates/sapg-response-to-covid-19/

76. The National Institute for Health and Care Excellence. COVID-19 rapid guideline: antibiotics for pneumonia in adults in hospital [Internet]. 2020. Disponible en: https://www.nice.org.uk/guidance/ ng173/resources/prescribing-tables-to-guide-decision-makingabout-antibiotic-choice-pdf-8719038253

77. British Society for Antimicrobial Chemotherapy. COVID-19 pandemic challenges all aspect of healthcare including both recognition and management of serious acute bacterial infection and effective delivery of antimicrobial stewardship [Internet]. 2020. Disponible en: http://bsac.org.uk/antibiotic-prescribing-in-the-context-ofcovid-19-pandemic/

78. The Sinai Health System-University Health Network Antimicrobial Stewardship. Program developed educational materials for patients on COVID-19 medication myths and the status of knowledge and research on drugs to prevent and manage COVID-19 [Internet]. 2020. Disponible en: https://4d9cc926-c314-41ac-908e-19322efdf1db. filesusr.com/ugd/b5d454_a296769261b54e4983cbeb5040f43ae7.pdf

79. Spernovasilis NA, Kofteridis DP. COVID-19 and antimicrobial stewardship: what is the interplay?. Infect Control Hosp Epidemiol. 2020: 1-2.

80. Publique Haut Conseil de la Santé Publique. Relatif à la prévention et à la prise en charge des patients à risque de formes graves de COVID-19 ainsi qu'à la priorisation des tests diagnostiques [Internet]. 2020. Disponible en: https://www.hcsp.fr/Explore.cgi/Telecharger? 
NomFichier=hcspa20200331_corsarcovprienchadesperrisdeforg.pdf

81. Alhazzani W, Møller MH, Arabi YM, Loeb M, Gong MN, Fan E, et al. Surviving Sepsis Campaign: guidelines on the management of critically ill adults with Coronavirus Disease 2019 (COVID-19). Crit Care Med. 2020; 48(6): e440-69.

82. Zhou Q, Gao Y, Wang X, Liu R, Du P, Wang X, et al. Nosocomial infections among patients with COVID-19, SARS and MERS: a rapid review and meta-analysis. Ann Transl Med. 2020; 8(10): 629.

83. Yagui-Moscoso MJ, Tarqui-Mamani CB, Sanabria-Rojas HA, Encarnación-Gallardo EE. Evaluación de las prácticas de control de infecciones de los trabajadores de la salud en un hospital de Lima Metropolitana, durante la epidemia de Influenza A H1N1. Rev Salud Pública. 2012; 14(2): 271-81.

84. World Health Organization. Regional Office for Western Pacific Routine immunization services during COVID-19 pandemic [Internet]. 2020. Disponible en: https://apps.who.int/iris/bitstream/ handle/10665/331925/Routine-immunization-services-COVID-19eng.pdf?sequence $=1$ \& isAllowed $=y$

85. Mendelson M. Could enhanced influenza and pneumococcal vaccination programs help limit the potential damage from SARSCoV-2 to fragile health systems of southern hemisphere countries this winter?. Int J Infect Dis. 2020; 94: 32-3.

86. WHO Global Infection Prevention and Control Network. Infection prevention and control during health care when COVID-19 is suspected [Internet]. 2020. Disponible en: https://www.who.int/publicationsdetail/infection-prevention-and-control-during-health-care-whennovel-coronavirus-(ncov)-infection-is-suspected-20200125

87. European Centre for Disease Prevention and Control. Infection prevention and control for COVID-19 in healthcare settings-third update [Internet]. 2020. Disponible en: https://www.ecdc.europa. eu/en/publications-data/infection-prevention-and-control-andpreparedness-covid-19-healthcare-settings

88. National Center for Immunization and Respiratory Diseases, Division of Viral Diseases. Interim Infection Prevention and Control Recommendations for Patients with Suspected or Confirmed Coronavirus Disease 2019 (COVID-19) in Healthcare Settings [Internet]. 2020. Disponible en: https://www.cdc.gov/ coronavirus/2019-ncov/hcp/infection-control-recommendations. html

89. Thompson MG, Pierse N, Sue Huang Q, Prasad N, Duque J, Claire Newbern $\mathrm{E}$, et al. Influenza vaccine effectiveness in preventing influenza-associated intensive care admissions and attenuating severe disease among adults in New Zealand 2012-2015. Vaccine. 2018; 36(39): 5916-25.

90. Kuster SP, Shah PS, Coleman BL, Lam PP, Tong A, Wormsbecker A, et al. Incidence of influenza in healthy adults and healthcare workers: a systematic review and meta-analysis. PLOS ONE. 2011; 6(10): e26239.

91. Bonten MJM, Huijts SM, Bolkenbaas M, Webber C, Patterson S, Gault $S$, et al. Polysaccharide conjugate vaccine against pneumococcal pneumonia in adults. N Engl J Med. 2015; 372: 1114-25.
Correspondencia:

Giancarlo Willmer Pérez Lazo

Dirección: Av. Grau N. ${ }^{\circ}$ 800, Lima 13, Perú.

Teléfono: 51-1 324-2983 anexo 44082.

Correo electrónico: diamantdust@hotmail.com

Recibido: 18 de junio de 2020

Evaluado: 30 de agosto de 2020

Aprobado: 05 de setiembre de 2020

๑ La revista. Publicado por Universidad de San Martín de Porres, Perú. (cc) $\mathbf{B r}$ Licencia de Creative Commons Artículo en acceso abierto bajo términos de Licencia Creative Commons Atribución 4.0 Internacional. (http://creativecommons.org/licenses/by/4.0/)

ORCID iDs

Giancarlo Pérez Lazo

Fernando Soto Febres

Adriana Morales Moreno

John Cabrera Enríquez

Janett Díaz Agudo

Rocío Rojas Tovar

Berenice Arenas Ramírez

Ricardo Illescas Mucha
- https://orcid.org/0000-0003-3823-4737

(- https: / / orcid.org/0000-0001-9491-6412

(1) https: / / orcid.org/0000-0002-5353-5266

(ㄱ https: / / orcid.org/0000-0002-0770-505X

(1) https: / / orcid.org/0000-0003-2967-9400

(1) https: / / orcid.org/0000-0001-7809-0366

(1) https: / / orcid.org/0000-0003-2480-8752

(1) https: / / orcid.org/0000-0001-9050-0241 